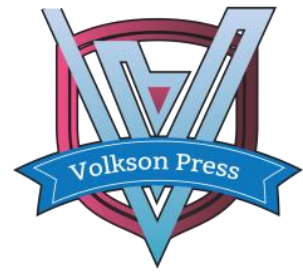

Contents List available at VOLKSON PRESS

Economics \& Management Innovations(EMI)

DOI : http://doi.org/10.26480/icemi.01.2017.68.70

\title{
Research on Information Disclosure Problem of Non-Profit Organizations in China
} and Its Countermeasures

\author{
LIU LAN ${ }^{1,}$, GENG JING ${ }^{2}$, SHEN YING ${ }^{3}$ \\ ${ }^{1}$ School of Economics and Management, Chongnam National University, Korea \\ ${ }^{2}$ School of Economics and Management, Yanbian University, China \\ ${ }^{3}$ School of Economics and Management, Yanbian University, China \\ *lynnliu29@163.com \\ This is an open access article distributed under the Creative Commons Attribution License, which permits unrestricted use, distribution, and reproduction in any \\ medium, provided the original work is properly cited.
}

\section{ARTICLE DETAILS}

\section{Article History:}

Received 02 october 2017 Accepted 06 october 2017 Available online 11 october 2017

\section{Keywords:}

non-profit

information

organizations;

organizational behavior; huma resources

\section{ABSTRACT}

Information disclosure by non-profit organizations in China has multiple problems such as incomplete disclosure, untimely disclosure and insufficient information construction of disclosure channels. There are multifaceted reasons behind the problem. Seen from internal and external factors, there are lack of organizational culture within the organization, dilution of the core values and slackness of subjective consciousness; intervention of administrative system makes non-profit organizations lack autonomy and sense of competition, and the accounting system cannot meet the public demand for financial information, etc.; talent and funds are insufficient; internal management of non-profit organizations including financial information disclosure system is imperfect; external laws and regulations are imperfect, accounting system of administrative institutions and civil non-profit organizations are inconsistent in content, time and object of financial information disclosure; government and social supervision are imperfect, relevant departments fail to observe laws and regulations and refrain from punishing lawbreakers in government supervision and law enforcement, low degree of punishment causes low cost in violations of laws and regulations, non-profit organizations do not have motive to abide by regulations with cost; in social supervision, a recognized third-party evaluation system has not yet formed to promote healthy competition among non-profit organizations.

\section{Introduction}

China's "Accounting System of Non-Profit Organizations" points out that non-profit organizations should meet the following three conditions: "not for profit purposes; any unit or individual does not have the ownership of non-profit organization via contribution of capital; balance of payments shall not be allocated to investors; once liquidation is done, surplus property of non-profit organizations after the liquidation should continue to be used for social welfare as required."

In general, nonprofit and public welfare are the fundamental features that distinguish non-profit organizations from other economic organizations. In the unique development process of China's non-profit organizations, government's financial support has become an important force in its establishment and development. Many non-profit organizations are directly run by government and belong to the government system. In our country, administrative unit refers to all kinds of state organs and political parties at all levels. Institutions are organizations engaged in social services that are established by state organs or with state assets. For instance, Red Cross Society of China belongs to public welfare organizations in social organizations, but also belongs to state administrative institutions in nature with independent legal personality. Since the reform in 2013, Red Cross Society of China applies "Accounting System of Civil Non-Profit Organizations" and "Accounting System of Administrative Units". In this paper, research object of non-profit organization refers to social organization with legal personality registered in civil affairs department, hereinafter referred to as non-profit organization

2. The main issues in information disclosure of non-profit organization

\subsection{Information disclosure by different non-profit organizations is} uneven

Due to great varieties and complexity of our country's non-profit organizations, applicable legal norms are different, and specific specifications and requirements for information disclosure are different.
Thus, there are inconsistencies and disunities in non-profit organizations practice of information disclosure. For instance, non-profit organizations belonging to administrative institutions in nature apply accounting system of administrative units or institutions, while other organizations apply "Accounting System of Civil Non-Profit Organizations". In other cases, Red Cross Society of China, etc. apply to "Accounting System of Administrative Units" and "Accounting System of Civil Non-Profit Organizations" at the same time. In addition, social organizations, foundations and private nonenterprises have separate management regulations respectively which have different requirements for their financial information disclosure.

\subsection{Financial information disclosure content is incomplete}

Completeness of information disclosure contents has been clearly stipulated in "Accounting System of Civil Non-Profit Organizations" implemented since 2005. However, in actual practice, financial accounting reports disclosed by many non-profit organizations are not standardized with incomplete contents. Take Red Cross Society of China for example, as of May 2017, on its official website, there has been only 2016 financial statement audit report disclosed, lacking audited financial reports from 2013 to 2015 since it applied "Accounting System of Civil Non-Profit Organizations" in 2013, which is not in compliance with specific specifications for complete disclosure of financial reports to the outside. Further investigation of completeness of the specific contents of disclosed audit reports reveals that financial report attached to the 2016 annual audit report of Red Cross Society of China contains only the balance sheet, income statement and cash flow statement, without any notes. Therefore, standardization of disclosed contents and statement title of audit report disclosed by Red Cross Society of China lacks perfectness and preciseness.

\subsection{Financial information disclosure is not timely}

Timeliness of financial information disclosure has been expressly stipulated in "Accounting System of Civil Non-Profit Organizations": "The annual financial and accounting reports of non-profit organizations should be provided to the outside at least within four months after the end of the year"1. But "Accounting System of Administrative Units" does not have clear time requirements for financial information disclosure, resulting in 
late financial information disclosure in non-profit organizations belonging to administrative units in nature. For instance, Red Cross Society of China disclosed final settlement of 2015 on July 22, 2016, disclosed final settlement of 2014 on July 17, 2015, which does not meet the four-month period requirements for civil non-profit organizations.

\subsection{Insufficient information construction}

First, information disclosure channels are scattered. Large organizations disclose financial information represented by financial reports or audit reports on their official websites and third-party websites, while many small and medium-sized non-profit organizations do not have relatively complete official website for financial information disclosure due to lack of necessary capital investment; disclosed contents of various information platforms have duplication, the public access to information is difficult, and there lacks systematic information disclosure platform.

Second, information channels lack specialized construction. For instance, Red Cross Society of China discloses financial information on "notice and announcement" on its official website. Nevertheless, "notice and announcement" includes not only disclosure of financial information, but also notice concerning organization and management. Moreover, there lacks classified management and disclosure, as information is mixed together, and it is difficult to find and identify disclosure of specific financial information.

Finally, financial information disclosure on the network lacks good interaction, as much is one-way information, there is no information search function, query is inconvenient. According to nonprofit characteristics of non-profit organizations and the public's need for supervision and awareness, non-profit organizations should innovatively disclose financial information in forms other than financial reports and audit reports, for instance source and management information of donations, and improve effectiveness of public inquiry experience with information technology such as information exchange technology. Currently, in official websites of Red Cross Society of China in provinces, except that Shanghai Branch, Jiangsu Branch and Qinghai Branch of Red Cross Society of China set up donation information release platform with interactive query function on their official website, branches in other provinces fail to set up the platform, generally disclosing donation information on "bulletin board", "love list" or "donation publicity". The one-way disclosure without interaction makes the donor unable to quickly, conveniently and specifically search whether an individual donates and how much is donated. Hence, information construction of information disclosure should be strengthened to improve quality and effectiveness of financial information disclosure.

\section{Cause analysis of information disclosure problem in non - profit organizations}

\subsection{Non-profit organizations lack awareness in information disclosure}

For information disclosure problem of non-profit organizations, the fundamental reason lies in non-profit organizations themselves. Organizations are composed of people in the final analysis, and one important point in seeking organization development is to seek development of people in the organization. People have subjective initiative, which distinguishes people from other animals. Human subjective consciousness, thought can guide people's actions, affect people's behavior, which has an immeasurable role and significance in practice, material. In human subjective consciousness, values are fundamental, and value judgment of each person before action determines whether he will take the action, determines what action he will take, and determines the purpose, starting point and purpose of his action. It can be said that value shapes a person. The common values of each person in the organization constitute the organization's values, organizational values are the core connotation of organizational culture, organizational culture plays a role similar to subjective initiative in development of an organization, and importance of organizational culture have been earlier proven in successful enterprises in Japan. The deep reason for information disclosure problem of non-profit organizations in our country lies in lack of organizational culture construction of non-profit organizations, which leads to lack of consciousness of consciously disclosing information. And it is difficult to carry out practical action without subjective understanding. It can be seen that different non-profit organizations have different levels of disclosure willingness and different degrees of recognition on public benefit core values. These differences play an important role in information disclosure of non-profit organizations and constitute the important reason for information disclosure gap.
3.2 Impact of limitations of administrative system on information disclosure

Administrative color of official non-profit organizations leads to their duality in operation and positioning. As social organizations, they have essence of administration, and their social status is derived from their own administrative and policy advantages. The limitations of administrative system are mainly reflected in the following three aspects: First, as an administrative institution, its finance is not open, and its information is not transparent. In "Accounting System of Administrative Units" and "Accounting System of Public Institutions", there is no specification on responsibility of financial information disclosure and disclosure time, which, however, is explicitly stipulated in "Accounting System of Civil NonProfit Organizations". Thus, comparability between the two is lacked. At the same time, budget, final settlement data required to be disclosed by administrative institutions only reflect expected cost and final cost of each item, and it is difficult for those highly general huge digits to reflect specific organization operation, as they lack comprehensibility compared to financial reports with detailed notes. Second, official non-profit organizations are monopolistic. This monopoly reduces their own sense of competition for resources, and it is difficult for other non-profit organizations to compete fairly. For instance, despite a series of sensational adverse events of Red Cross Society of China which put pressure on its managers to a certain extent, seen from competition for survival and development, its large scale and financial funds guarantees its strong competitive advantage compared to small and medium-sized non-profit organizations. Third, official non-profit organizations are subject to more government intervention, lack management autonomy, and basically have no independent personnel appointment and removal rights, as personnel recruitment is led by the government to recruit civil servants. Many civil servants only take their work as a means of subsistence rather than charity career, so they easily breed desire to seek selfish interests. Most of the leadership is additionally undertaken by officials in the government and party and government offices or abdicated officials. Many officials lack enthusiasm and professional level for public welfare, which affects organization independence, professionalism and operational efficiency to a large extent, thereby reducing enthusiasm of non-profit organizations in information disclosure and their importance attached to information disclosure.

\subsection{Limitations of resources required for financial information} disclosure

Limitations of internal resources of non-profit organizations and limited resources allocated to financial information disclosure constitute an important reason for insufficient financial information disclosure. These resources include human resources and funds required for financial information disclosure.

First, non-profit organizations lack human resources. Due to strong volatility of non-profit organizations, difficulty in raising funds and the public's concern about salary of non-profit organizations, salary package of non-profit organizations is not competitive compared with that of large enterprises, and it is difficult for them to attract high quality and professional talents in the talent market. As a result, there is few full-time staff, and it is difficult for volunteer team to meet professional skills needs like accounting, information processing and high-quality information disclosure requirements.

Another point is also the most direct constraint, lack of funds. The cost of information provision and processing of non-profit organizations includes two costs, on the one hand, the cost of collecting, collating, processing, auditing and transmitting information, and on the other hand, the cost of processing and answering needed by inquiry of disclosed information. ${ }^{2}$ These information costs account for a certain percentage of expenditure of non-profit organizations. And in today's big data age, the high cost of information construction based on cloud computing is out of reach for a lot of small and medium-sized non-profit organizations. At the same time, current non-profit organizations are generally faced with financial difficulties. To reduce the cost of information disclosure, non-profit organizations save capital costs to carry out core business activities: public welfare. Lacking necessary financial support, financial information disclosure inevitably has violations of understatement, failure in report and delayed report, etc.

\subsection{Internal information disclosure-relevant system is imperfect}

China's non-profit organizations ignore the importance of internal governance. First of all, it is difficult for imperfect internal governance such as internal control to control and monitor authenticity and objectivity of financial information. Secondly, imperfect financial system lacks 
procedural specifications for generation and processing of financial information, and cannot guarantee authenticity, completeness of financial information content as well as timeliness of information disclosure. Finally, imperfect information disclosure system of non-profit organizations will not clearly specify disclosure content, disclosure object and timely disclosure, which will greatly reduce operability of information disclosure. Official non-profit organizations and civil non-profit organizations apply different accounting systems. Official non-profit organizations apply "Accounting System of Administrative Units" and "Accounting System of Public Institutions". Fund-raising foundations apply "Accounting System of Civil Non-Profit Organization", while civil non-profit organizations apply "Accounting Law", "Accounting System of Civil Non-Profit Organization", "Social Groups Registration Management Regulations", "Provisional Regulations for Private Non-Enterprise Registration Management", "Foundation Management Regulations", etc. The three types of management regulations have different requirements for accounting and its financial disclosure of social groups, private nonenterprise units and foundations. In terms of stipulations on information disclosure timeliness and disclosure object, "Accounting System of Civil Non-Profit Organization" requires disclosure within 4 months after the end of the year, but accounting system of administrative units and public institutions does not specify disclosure time of financial reports; meanwhile, "Accounting System of Civil Non-Profit Organization" specifies responsibility for external disclosure, which is not the fact in accounting system of administrative units and public institutions. This inconsistent, non-uniform calculating system leads to lack of comparability, systematicness and standardization of non-profit organizations.

\subsection{External supervision mechanism of financial information disclosure is imperfect}

External supervision of information disclosure by non-profit organizations includes legal supervision, government supervision and social supervision. In government supervision, there are main problems of "absence of organization", slack law enforcement, failure to punish lawbreakers. At present, China practices dual management systems with non-profit organizations respectively managed by registration and business authorities. The multiple official supervision subjects lead to "absence of organization". Due to ambiguity of power and duties and mutual prevarication, unsupervised situation arises and weakens effectiveness of government supervision. Imperfect social supervision is reflected in imperfect development of independent third party evaluation agencies, as small number, immature development, not unified evaluation criteria and lack of accountability mechanism of third party evaluation institutions affect the role of third party social supervision forces.

\section{Conclusion}

In conclusion, in order to improve information disclosure of non-profit organizations, we should carry out construction of organizational culture with values as the core and improve subjective initiative of social workers and non-profit organizations; reform the administrative system, reduce government participation, stimulate the enthusiasm of social workers, improve work efficiency; standardize internal governance, improve the system of information disclosure of non-profit organizations; improve laws and regulations, establish and standardize a unified legal system with comparability; establish a comprehensive supervision mode, strengthen government supervision, promptly correct violations and make them known to the public, strengthen construction of third-party evaluation system to form benign competition among supervision by public opinions, public choice and non-profit organizations.

\section{References}

[1] Tian Xiaolu. Improve the information disclosure mechanism of nonprofit organizations in China. Pioneering with Science \& Technology Monthly, 2012 (1): 86

[2] Jiang Hongqing. Analysis of mechanism and approach of transparent information of non-profit organizations. Shandong Social Sciences, 2012 (2): 45

[3] Ministry of Civil Affairs of the People's Republic of China, 2015 Statistical Bulletin on Social Services Development, July 11, 2016

[4] Ministry of Finance of the People's Republic of China, "Accounting System of Institutions", effective from January 1, 2013

[5] Ministry of Finance of the People's Republic of China, "Accounting System of Administrative Units", effective since January 1, 2014 